\author{
영화에 나타난 대한제국기 신여성 의상 이미지 \\ - <가비>, <YMCA 야구단>, <그림자 살인>을 중심으로 -

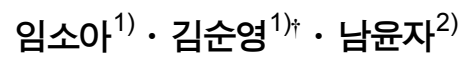 \\ 1)서울대학교 의류학과 \\ 2)서울대학교 의류학과/생활과학연구소
}

\title{
Costume Images of New Woman in the Korean Empire Period in Films - Focused on Gabi, YMCA Baseball Team, and Private Eye (Geurimja Sarin) -
}

\author{
Soa $\mathrm{Im}^{1)}$, Soon Young $\mathrm{Kim}^{1) \dagger}$, and Yun Ja $\mathrm{Nam}^{2)}$ \\ ${ }^{1)}$ Dept. of Textiles, Merchandising and Fashion Design, Seoul National University; Seoul, Korea \\ ${ }^{2)}$ Dept. of Textiles, Merchandising and Fashion Design/Research Institute of Human Ecology, Seoul National University;
} Seoul, Korea

\begin{abstract}
This study analyzes the visual image and the symbolic image of the 'New Woman' main female characters' costumes in three films: <Gabi >, <YMCA Baseball Team>, and <Private Eye (Geurimja Sarin) >, set in the Korean Empire Period and filmed in the last 10 years. The findings are as follows. First, on the visual image by formative characteristics, Gibson girl style was reflected in Western costume design. Korean costume design is based on a traditional style (or modified in some parts). Second, the three films have the same historical background on the visual image by the fidelity of historical research; however, the fidelity of historical research differs and varies with the personality of characters or situations in the films. Third, all three films share the symbolic image by characteristics of characters and 'New Woman' aspect with the same historical background and 'New Woman' female character in common; however, the personality and 'New Woman' aspect of the characters were somewhat different. There was also a distinct difference in the symbolic image of Western and Korean costumes. Western and Korean costumes signify externality versus internality and denial versus the affirmation of national identity in $<\mathrm{Gabi}>$; dailiness versus ceremonialness and dynamics versus statics in <YMCA Baseball Team > ; and independence versus conformity and variability versus continuity in $<$ Private Eye (Geurimja Sarin) $>$.
\end{abstract}

Key words : film costume(영화 의상), Western costume(양장), Korean costume(한복), visual image(시각적 이미지), symbolic image(상징적 이미지)

\section{1. 서 론}

대한제국기(1897 1910년)는 조선 왕조의 마지막 시기로서 봉 건적 사회 질서를 벗어나 근대적 체제로 이행하던 과도기적 시 기이다. 복식사적 측면에서는, 복식 개량 운동 등 한복의 변화 가 일어나고 서양 복식의 유입으로 인해 한복과 양장이 혼용되 기 시작한 시기이다.

영화는 인간의 내적 표상이 지각되는 형태로 전환된 매체이 다(Kim \&Kim, 2014). 사극에서 의상은 역사적 사실을 반영하 면서 특정 시대의 복식에 대한 시각적 정보를 관객들에게 제공 하기도 하고 감독의 의도에 따라 정교하게 연출된 이미지를 통 해서 관객들에게 의미 있는 연상 작용을 일으키기도 한다.

$\dagger$ Corresponding author; Soon Young Kim Tel. +82-2-880-6841, Fax. +82-2-875-8359 E-mail: soonyoung1.kim@gmail.com
Delong은 특정 대상이 관찰자에게 일으키는 연상을 '지각 연 상'과 ‘추론 연상'으로 분류했는데, 지각 연상은 형태에서 직접 적으로 지각할 수 있는 속성, 즉 선, 형, 색채, 표면 재질감 등 에서 비롯되는 연상이며, 추론 연상은 보다 간접적이고 추론되 는 것으로 우리가 흔히 '상징'이라 부르는 것이라 하였다 (Delong, 1987).

이러한 Delong의 복식 조형 의미 해석의 틀을 영화 의상에 적용해 보면, 영화 의상이 관객들에게 보여주는 이미지는 선, 형, 색채, 재질 등 의상의 조형적 요소들과 역사적 사실성에서 비롯되는 '시각적 이미지'와 보다 간접적이고 은밀한 '상징적 이미지'로 대별될 수 있다. 시각적 이미지는 영화의 표면에 직 접적으로 드러나며 누구나 이해하기 쉬운 의미 작용을 일으키 는 반면, 상징적 이미지는 감독에 의해 의도된 것으로서 영화 의 표면에 드러나지는 않지만 일부 관객들에게 심리적 연상을 일으킬 수 있는 영화적 장치라 하겠다. 
지금까지 개화기 복식에 관한 선행 연구를 살펴보면 남자 복 식과 여자 복식의 변천 과정(Lim et al., 1994; Yi \& Kim, 1995), 개화기 복식과 사상(Kim, 1989), 대한제국의 대례복 (Lee, 2008), 한국과 일본의 신여성복식 비교(Yu, 2007), 근대 복식의 수용(Yi \& Kim, 1995) 등 여러 주제의 연구들이 있었 다. 그러나 개화기를 배경으로 하는 영화나 드라마 의상에 대 한 분석 연구(Lee et al., 2006)는 적은 편이고, 특히 신여성 인물의 한복 의상과 양장 의상을 비교 분석한 연구는 거의 없 었다. 또한 지금까지 사극 영화 의상 분석에 관한 연구는 주로 조형적 특징이나 고증 관계 등 시각적 이미지 분석에 치중(Lee et al., 2006)한 경우가 많았으며, 상징적 이미지까지 연구 문제 를 확대한 경우가 많지 않았다. 특히 대한제국 시기를 시대적 배경으로 하여 당시 한복의 변화와 양장의 도입 양상이 영화에 서 어떻게 드러나고 있으며, 한복과 양장이 가지는 상징적 의 미 관계를 해석한 연구는 거의 없었다.

따라서 본 연구에서는 대한제국 시기를 배경으로 하는 세 편 의 영화를 선정하여, 이들 영화에서 신여성적 면모를 지니는 여 주인공들의 의상에서 드러나는 시각적 이미지와 상징적 이미지 를 해석하여 사극 영화 의상의 이미지에 대한 다각적이고 입체 적인 분석을 시도하고자 한다. 특히 한복과 양장의 이미지가 영 화적 장치 속에서 대비를 통해서 더욱 분명하게 드러나고 있음 을 밝힘으로써, 신여성 의상이 우리 내면에 내재된 한복과 양 장의 대조적 심상을 드러내고 있음을 부각시키고자 한다. 이를 통해 영화 의상의 역할에 대한 깊이 있는 이해를 도모하고, 영 화에 등장하는 한복과 양장 의상의 해석과 이해의 지평을 넓히 는데 기여하는 것을 목적으로 한다.

구체적인 연구 문제는 다음과 같다. 첫째, 조형적 특성과 고 증 충실도를 기준으로 각 영화의 신여성 의상의 시각적 이미지 를 분석한다. 둘째, 인물 특성과 신여성적 면모를 토대로 각 영 화의 신여성 의상의 상징적 이미지를 분석한다.

본 연구는 문헌 연구와 영화 장면 분석을 통해 이루어졌다. 연구에 이용된 문헌 자료는 근대 복식사 및 신여성 이미지 관 련 선행 논문들과 개론서 등이다. 분석 대상이 된 영화는 최근 10 여년 이내 개봉된 국내 영화 중, 시대적 배경이 1896 1907 년에 해당하는 세 편의 영화 <가비>(2011년 제작), <YMCA 야구단>(2002년 제작), <그림자 살인>(2009년 제작)이다. 이처 럼 제작 시기와 시대적 배경이 비슷하도록 분석 대상을 좁혀, 각 영화에 등장하는 여주인공의 의상을 살펴보았다. 실제 대한 제국 시기는 1897 년 10 월에서 1910년 8월까지로, 세 영화의 배경이 되는 시기보다 1 년 늦은 1897년부터이지만, 세 영화의 시대적 배경 대부분이 대한제국 시기에 해당하므로 이들 영화 를 모두 대한제국을 배경으로 하는 영화로 보았다. 선정된 세 편의 영화에서 여주인공들은 모두 신문물을 접했거나 신식 교 육을 받은 신여성적 특성을 지니고 있으며, 한복과 양장을 혼 용하는 유일한 여자 인물이다. 따라서 의상 분석의 대상을 여 주인공으로만 한정하여 이들의 한복과 양장 이미지를 분석하였 다. 이미지 분석을 위해 영화 장면을 캡쳐하여 사용하였다.

\section{2. 이론적 배경}

\section{1. 개화기의 여성 복식 변화}

개화기는 일반적으로 1876 년 개항 이후에서 1945 년 일제 강 점기 종료까지의 시기를 말한다. 개화기 내에서도 1897 년 10 월 12일부터 1910년 8월 29일까지 존속하였던 조선왕조의 마지막 국가를 대한제국이라 부른다(National Palace Museum of Korea, 2010). 개화기는 외국의 문화를 받아들여 재래의 것과 는 다른 문화를 창조했던 시기이며, 전통적인 이념과 가치관에 획기적 변화를 일으킨 시기이다(Choi, 2001). 근대화가 진행됨 에 따라 서구의 의복 문화가 유입되었고, 그 영향으로 계급사 회에 맞게 복잡한 양식이었던 전통 복식은 점차 단순화되고 간 편화되었다. 이 시기에 '양복'에 대응되는 개념으로 '한복'이라 는 단어가 생겨났으며, 전통 양식은 일부만을 남기고 재구성되 어 갔다(Jeon et al., 2004).

여자 한복의 변화를 살펴보면, 19세기 후반부터 단소화되었 던 여자 저고리는 1910년대까지 17 20 cm 길이로 극도로 짧아 졌으며 소매는 팔에 꼭 끼는 정도였다(Choi, 2001). 여자의 짧 은 저고리에는 가슴띠를 반드시 이용해야 했으며, 이후 저고리 길이가 점차 길어지고 품도 조금 넉넉한 형태로 변하게 되었다 (Kim \& Yim, 2009). Fig. 1은 1900년대 후반 1910년대 후반 무렵의 사진으로 추정되는데, 이 사진에서 여자 저고리의 길이 가 극도로 짧은 것과 약간 길어진 것이 공존하고 있었음을 알 수 있다(Busan Modern History Museum, 2009). 치마는 자락 치마와 통치마가 혼용되었다. 전통적인 자락치마는 말기를 달 아 허리나 가슴에 둘러 입는데 반해, 통치마는 서양 남성의 조 끼모양을 고안하여 만든 상의 부분을 치마에 달아 어깨에 걸치 도록 한 것이었다(Kim \& Yim, 2009).

여자 한복의 형태 변화는 주로 천주교와 개신교 등 종교 및 신교육에 따른 의식 변화를 겪은 여성들에 의해 주도되었다. 신 식 여학교의 학생들은 초기에는 주로 재래식 저고리와 자락치 마를 입었지만, 점차 통치마와 같이 변형된 한복을 교복으로 입 기 시작했다. 1907년 동경 유학생 최활란이 귀국하여 히사시카 미 머리에 양말과 구두, 검정색 짧은 통치마를 입었는데, 이 차 림은 그 후 선풍적 유행을 일으키게 되었다(Go, 2001). 1908 년 개교한 한성여학교는 학생들의 교복으로 검정 통치마와 흰 저고리를 채택하였다. 이는 당시 교장의 선택으로서, 외출시 너 울이나 장옷으로 얼굴을 가리는 것을 폐풍이라 보고 이를 타파 하는 동시에, 여성의 체위 항상과 활동 능률을 높이기 위한 목 적에서였다(Go, 2001).

한복의 외형이 조금씩 변화됨과 동시에 여성의 양장 착용도 점차 증가했다. 양장은 서양문물을 먼저 접할 수 있었던 왕족 이나 외교관 부인과 같은 일부 특권층 여성들이나 유학생들, 신 식 여학교의 학생들로부터 소개되기 시작했다. 궁중에서 양장 을 제일 먼저 착용한 사람은 고종황제의 계비 엄비로 알려져 있다. Fig. 2와 같이 모자를 쓰고 퍼프소매의 드레스에 장갑을 끼고 양산을 든 엄비의 사진이 있는데, 이 사진의 촬영 시기는 


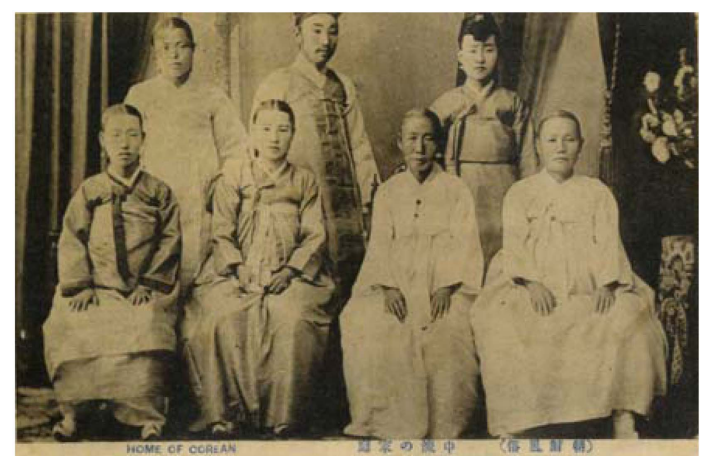

Fig. 1. A family in the traditional Hanbok. The Journey to the Modernity (2009), p. 275
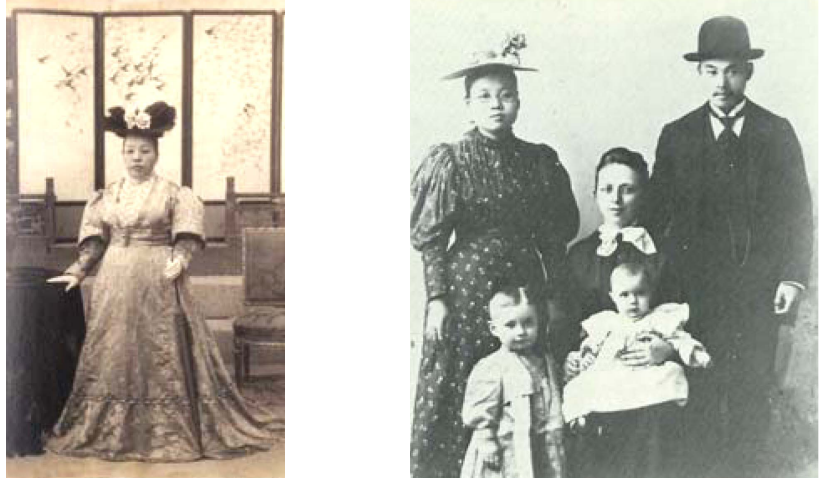

Fig. 2. Queen Eombi in Western Fig. 3. Esther Pak in Western dress in 1895. dress. 100 Years Past: Memories of http://blog.joins.com/media/index.asp? uid $=s$ the Korean Empire (2010), p. 201. pirit0104\&folder $=0 \&$ day $=200901^{\prime}$
1907년경으로 추정되고 있다(National Palace Museum of Korea, 2010). 일반인 가운데 비교적 이른 시기에 양장을 착용 한 여성들로는 미국 유학의 경험이 있는 윤고려(윤고라), 박에 스더, 하란사 등이 알려져 있다(Go, 2001). Fig. 3에서 퍼프 소매의 원피스를 착용한 박에스더의 모습을 볼 수 있다.

엄비와 박에스더 등 여성들의 양장 차림에서는 당시 서양에 서 유행하던 S커브 실루엣의 '깁슨 걸 룩(Gibson girl look)'이 엿보인다. 깁슨 걸 룩은 찰스 다나 깁슨(Charles Dana Gibson) 이 1895 년에서 1910 년까지의 기간 동안 그렸던 잡지 스케치에 서 유래된 말로서 그의 스케치는 당시의 이상적 젊은 여성상으 로 받아들여졌다(Calasibetta, 1998/2006). Fig. 4 Fig. 6에 보 이는 바와 같이 깁슨 걸 룩은 목선이 높게 올라오는 칼라와 턱(tuck)과 레이스로 장식한 블라우스, 레그 오브 머튼 소매 (leg-of-mutton sleeve), 뽕빠두르(pom-padour) 스타일의 머리와 개더 스커트 등을 특징으로 한다(Calasibetta, 1998/2006).

1907년 이후에는 일부 여학교에서 양장을 교복으로 채택하 기도 했으며 양장점이 개점되기도 했다. Fig. 7은 1907년 숙명
여학교에서 채택한 양장 교복으로, 밀짚모자와 퍼프소매의 원 피스 차림이다(Park, 2012). 1907년 진명여학교에서 도입한 양 장 교복은 여름에 보닛 모자를 쓰고 원피스 형태의 양장을 입 고 구두를 착용하는 것이었다(Go, 2001). 1907년 세브란스 간 호원 양성소의 간호원복도 양장이었으며, 1908년에는 서울에 양장 전용점인 ‘부인양복점'이 문을 열었다(Go, 2001).

\section{2. 개화기의 신여성}

'신여성'에 대한 사전적 정의는 크게 다음 두 가지, '개화기 때 에 신식 교육을 받은 여자'와 '개화기 때에 서양식 차림새를 한 여자'이다(The National Institute of the Korean Language, 2008). 두 가지의 사전적 정의에도 불구하고 신여성에 대한 정 의에는 여전히 불명확한 부분이 존재한다. 1990년대 이후 신여 성 연구가 활발히 이루어졌으나 정작 신여성이 어떤 범주였고 구체적으로 어떤 의미를 가진 용어였는지에 대해서는 본격적인 논의와 합의가 아직 이루어지지 않았다(Jo, 2013; Kim, 2009). 신여성 현상은 후기 빅토리아 시대(1883 1890년) 영국의 ‘뉴
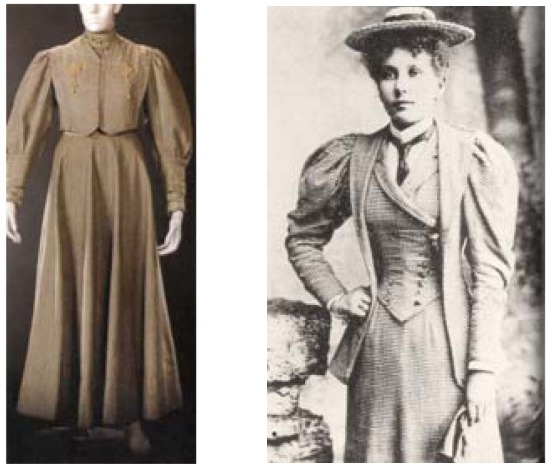
Fig. 4. Gibson style Fig. 5. A Woman in Gibson Fig. 6. Plating skirt set.
walking suit. 100 Years style walking suit. 100 Years 100 Years of Western of Western Costume in of Western Costume in Korea Costume in Korea Korea (2008), p. $18 . \quad$ (2008), p. 18.
(2008), p. 23.

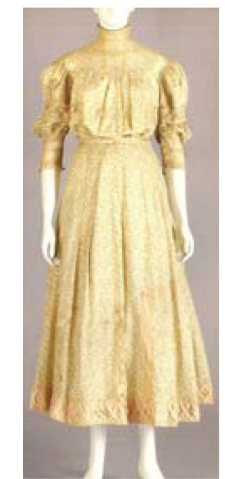

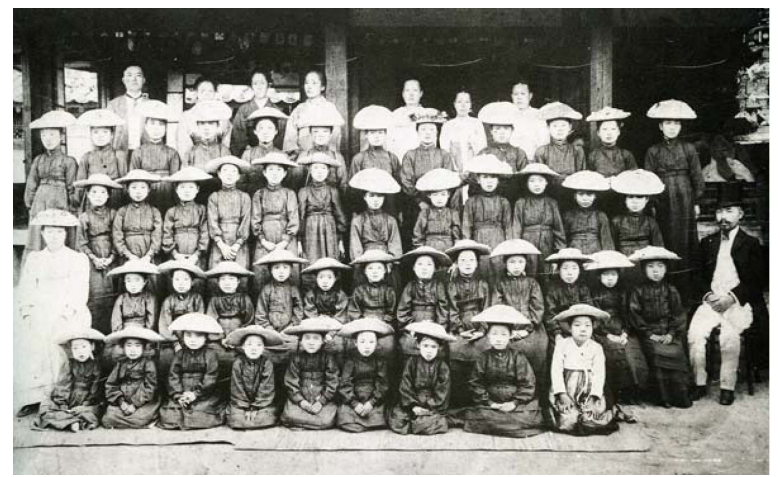

Fig. 7. Purple British school uniform of Sookmyung girls' school students (1907). http://www.heritagechannel.tv/hp/hpContents/story/ view.do? contentsSeq $=927 \&$ categoryType $=2$ 
우먼(New Woman)' 열풍에서 시작하여 곧 유럽을 비롯한 세계 각국으로 퍼져 나가 여러 언어로 번역되며 대중매체, 도시, 학 교 등에서 그 형상이 발견되었고(Kim, 2009), 각 사회에서 신여 성들은 중등교육이나 고등교육을 받은 초기 세대들로서 이전에 는 볼 수 없었던 새로운 가치와 태도를 추구하는 존재로 등장하 였다(Kim, 2009). 이러한 배경을 바탕으로 본 연구에서 신여성 은 개화기 때에 신식 교육을 받은 여자로서 이전 시기에는 볼 수 없었던 새로운 가치와 태도를 추구하는 존재로 정의된다.

개화기의 일부 여성들은 교육을 통해 신지식을 얻었고 추후 유학, 취직 등 사회 진출의 기회를 얻을 수 있었다. 조선시대 사회를 지배한 내외법에 따르면 여성은 아버지, 남편, 아들 등 가정 내의 남성에게 의존해 살아가야만 했기 때문에, 1886 년에 설립된 우리나라 최초의 근대적 여성교육기관인 이화학당의 초 기 여학생들은 내외법을 따라 가문의 명예를 지킬 필요가 없는 계층인 고아들이나 가난한 집안 출신들이 대부분이었다(Jeong, 2001). 개화기 여성 교육의 초기 단계에서는 여학생들이 소학 교를 졸업한 후 전문학교에 진학하거나 유학을 가고 싶어 한다 해도 부모들은 딸들이 가사를 배우다 좋은 조건으로 혼인하기 만을 희망하였다(Jeong, 2001). 여성에게 지식이 필요하다면 그 것은 가정 일을 잘 수행하고 남편을 잘 내조하기 위한 것일 뿐 세계를 확장하는 창조적 과정으로 받아들여지지 않았기 때 문이다(Jeong, 2001).
1898년 우리나라 역사상 최초의 여권 선언서인 <여권통문> 에서 여성의 사회진출을 강력히 주장하고 있지만, 여성이 사회 진출이 민족 사회의 발전에 반드시 필요하다는 사회적 인식이 확대된 것은 일제의 한국 침략이 적극화되었던 1905년 이후였 다(National Institute of Korean History, 2003). 그리고 거리 곳곳에서 학교를 다니는 여자들을 쉽게 볼 수 있는 것은 1920 년대 이후가 되어서였다(Suyu+Nomo Modern Media Research Team, 2005). 이처럼 신식 교육과 여성의 사회 진출에 대한 필 요성을 인식한 사람들이 개화기 초부터 일부 있었지만, 그 인 식이 대중화되는 데에는 상당한 시간이 필요했다.

본 연구에서 다루는 영화들의 시대적 배경이 되는 대한제국 기는 한국 사회에서 신여성에 대한 인식이 대중화된 시기로 보 기는 어려우며, 대중화의 진행 과정 초기에 있었던 시기로 이 해할 수 있다. 영화에 등장하는 여주인공들은 이런 대중화의 초 기 단계에 존재했을 법한 가상적인 인물들이다. 따라서 여주인 공들의 신여성적 면모를 이해하기 위해서 개화기 당시 신여성 적 면모를 갖춘 실제 여성 인물들의 행적을 간단히 살펴보는 것이 도움이 될 것으로 생각된다.

최초의 여의사로 알려진 박에스더는 선교사인 아펜젤러 밑 에서 일하며 일찍이 서양사상을 접한 아버지 덕분에 1886년 이 화학당에 입학하게 됐고, 이후 1900년 미국에서 한국여성 최초 로 의학박사 학위를 받았으며 귀국하여 여의사로서 활동했다

Table 1. Costumes of the main female character in $<\mathrm{Gabi}>$

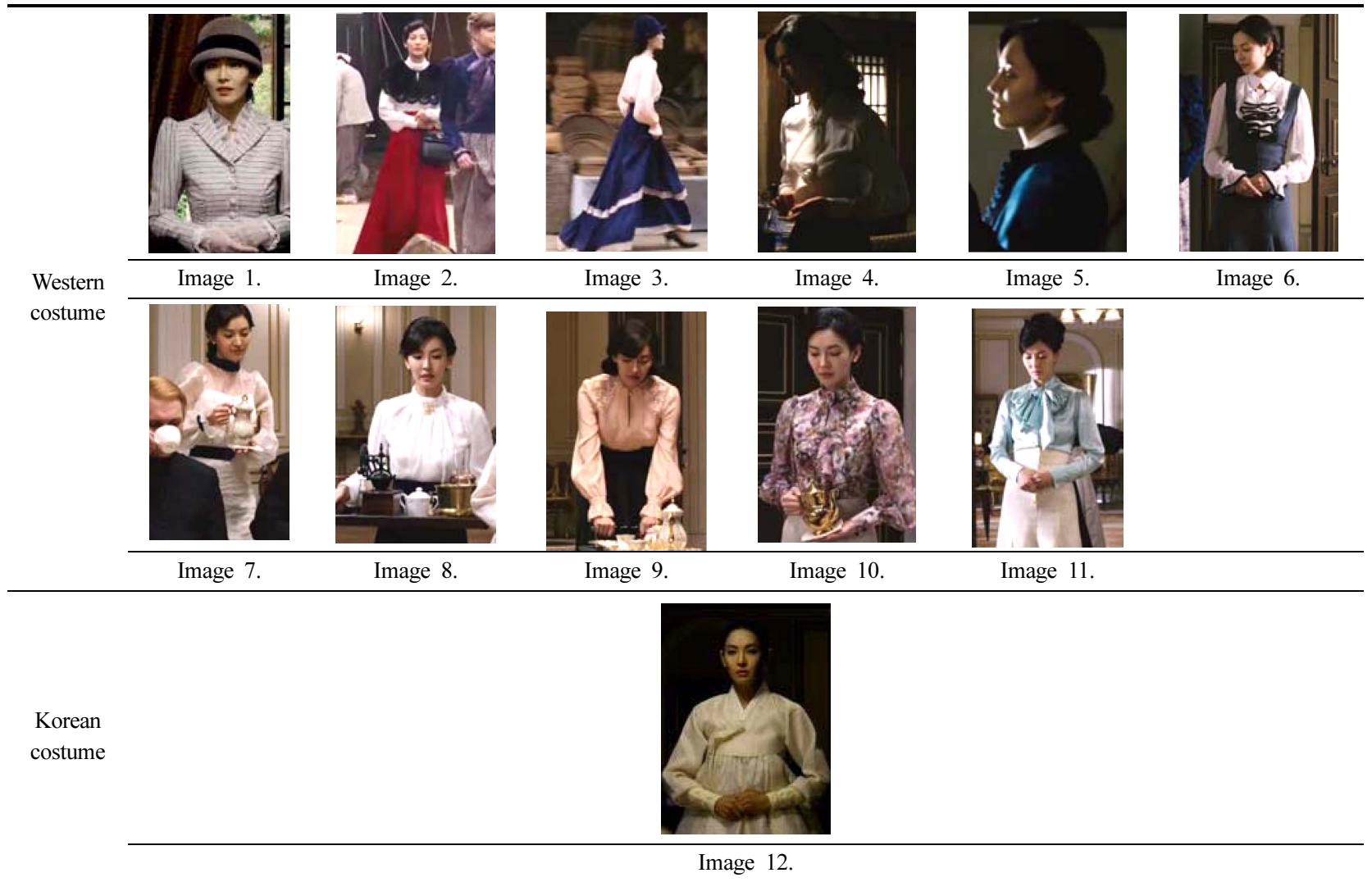

Media Content :Image 1 12. Costumes in $<$ Gabi $>$. $<$ Gabi $>$ official DVD (November 22nd 2013). 
(Lee, 2005). 최초의 여학사이자 독립운동가인 하란사는 1896 년 이화학당에 입학했고 이후 일본 유학을 다녀온 후 다시 1900 년 미국에 유학하여 1906년 한국 여성 최초로 학사 학위를 받았 다. 하란사는 사회 여러 방면에서 두드러진 활약을 했으며 고종 과 엄비의 자문가 역할을 하기도 했다(Lee, 2005). 시대를 앞서 간 여류 서양화가로 알려진 나혜석은 1896년 증조부가 호조참판 을 지낸 명문가에서 오남매 중 둘째 딸로 태어났는데, 구한말 군 수를 지낸 부친 나기정은 일찍이 개화사상을 접하면서 다섯 자 녀 모두 신식 교육을 받게 하였다(Lee, 2005). 나혜석은 1910 년 수원 삼일여학교를 거쳐 1913년 진명여학교를 졸업하고 일 본 도쿄의 여자미술학교에 입학해 한국 여성으로는 최초로 서 양 미술인 유화를 전공하게 됐다(Lee, 2005).

\section{3. 영화의상의 시각적 이미지}

\section{1. 가비}

$<$ 가비>의 배경은 을미사변 후 고종이 러시아 공관으로 1년 여 동안 피정한 아관파천(1896년)과 대한제국 선포(1897년) 사 이의 시기이다. 여주인공 따냐가 일본의 포로이자 첩자가 되어 바리스타로 위장해 고종 암살 작전에 연루되는 과정을 그렸다. $<$ 가비>에서는 따냐의 의상이 총 17 벌 등장하는데, 그 중 양장 은 16 벌, 한복은 1 벌이다. 16 벌의 양장 가운데 5 벌은 따냐가 러시아에서 도적 생활을 할 때나 위장용 또는 유니폼으로 착용 했던 의상으로 특수한 장면의 상황에서 연출된 의상이므로 본 연구의 성격과 맞지 않아 제외하였다. 나머지 11 벌의 양장과 1 벌의 한복에 대해 영화의 전개 순서대로 번호를 붙여 정리한 결과는 Table 1 과 같다.

먼저 조형성을 살펴보면, 따냐의 양장은 기본적으로 당시 서 양에서 유행했던 깁슨 걸 스타일을 반영하고 있다고 볼 수 있 다. 실루엣은 전반적으로 $\mathrm{S}$ 자형 실루엣이며, 레그 오브 머튼 소 매(leg-of-mutton sleeve)의 재킷과 가는 허리를 강조하는 긴 치마, 리본 디테일의 셔링 블라우스 등으로 여성스러운 분위기 를 드러내었다. 색상은 흰색과 아이보리색, 검은색과 남색을 주 로 사용했으며 살구색, 하늘색 등의 파스텔 톤과 빨간색을 추 가로 배색하였다. 소재는 쉬폰과 트위드 등을 사용하여 고급스 러운 이미지를 연출하였다. 따냐가 궁녀가 되기로 결심한 후 궁 녀로서 착용했던 1 벌의 한복을 제외하면, 따냐의 의상은 모두 양장이었다. 고급스럽고 화려한 양장을 다양하게 착용하여 기 품 있고 우아한 이미지를 보여주었다.

따냐 의상의 고증 충실도를 살펴보면, 양장의 경우 영화의 실제적 시대 배경보다 후대의 것으로 추정되는 일부 의상들을 사용하고 있는 것이 눈에 띈다. 날염 프린트 블라우스(Image 10)나 시스루 소재의 블라우스(Image 7) 등이 영화의 배경이 되는 시대보다 후대의 것으로 보인다. 양장의 경우 시대적 배 경 당시의 조형성을 완전히 무시하지는 않았지만 정확한 고증 보다는 의상을 통한 분위기 연출이나 다양한 디자인에 더 중점
을 두었다고 볼 수 있다. 따냐가 착용한 한복(Image 12)은 보 통의 궁녀복과 달리 저고리와 치마가 모두 백색이었다. 이는 영 화의 시간적 배경이 명성황후의 국상기간에 해당하므로 국상복 인 천담복(线淡服)을 연출한 것으로 이해된다. 저고리의 외형을 보면 상체에 꼭 끼었던 당시 저고리보다는 전반적으로 여유로 운 모습이며, 다소 넓은 깃과 동정 등에서 현재의 한복 유행이 반영된 것을 볼 수 있다.

\subsection{YMCA 야구단}

$<\mathrm{YMCA}$ 야구단>은 을사조약이 체결된 1905년을 시대적 배 경으로, $\mathrm{YMCA}$ 에서 조직한 조선 최초의 야구단 이야기를 소재 로 다루고 있다. $\mathrm{YMCA}$ 교사인 여주인공 민정림과 미국인 선 교사들을 주축으로 야구단이 결성되는 과정에서 항일 운동 등 당시의 시대적 배경과 관련된 여러 가지 이야기가 전개된다. $<\mathrm{YMCA}$ 야구단>에서 민정림의 의상으로 총 12 벌의 의상이 등 장하는데, 그 중 양장은 11 벌, 한복은 1 벌이다. 11 벌의 양장 가 운데 야구단 유니폼은 특수한 상황에서 착용된 의상이므로 본 연구의 성격과 맞지 않아 제외하였다. 나머지 10 벌의 양장과 1 벌의 한복에 대해 영화의 전개 순서대로 번호를 붙여 정리한 결과는 Table 2와 같다.

먼저 조형성을 살펴보면, 민정림의 양장은 전반적으로 $\mathrm{S}$ 자형 실루엣을 보여주고 있지만 <가비>의 따냐가 착용하고 있는 의 상들에 비해 깁슨 걸 룩의 특징적 요소들을 덜 드러낸다고 볼 수 있다. 치마는 허리를 강조하고 아랫단으로 갈수록 퍼지는 형 태가 많고, 색상은 흰색을 기본으로 하여 파란색과 분홍색 계 열을 많이 사용하였다. 소재는 면, 마 등의 실용적 소재가 많 이 보인다. 아버지의 장례 때 입은 1 벌의 상복을 제외하고 민 정림의 의상은 모두 양장이었다. 민정림의 양장은 간소하고 소 박한 외관을 통해 밝고 활동적인 이미지를 드러내는 경우가 많 았다. 발목 길이의 스커트, 실크처럼 값비싼 소재가 아닌 면, 마, 간단한 레이스 등의 실용적인 소재를 통해 활동성, 생기발랄 함, 경쾌함 등의 이미지를 드러내었다. 장면의 성격에 따라 때로 는 여성적이면서 귀여운 이미지를 표출하는 경우도 있었다. 부 드러운 느낌의 파스텔 톤 색상을 간간히 사용하고, 여성스러운 레이스 디테일 장식, 칼라와 소매 등에 삽입된 부분적 장식 등 을 통해 사랑스럽고 밝은 이미지를 보여주었다.

민정림 의상의 고증 충실도를 살펴보면, 양장의 경우 깁슨 걸 룩에서 보이는 바와 같이 허리를 조이는 $\mathrm{S}$ 자형 실루엣을 기 본으로 하고 있지만, 당시 복식과 비교해 볼 때 소매의 모양이 나 레이스 디테일 등에서 많은 변형(Image 13, 17, 19)이 있 어 고증에 충실한 것으로 보기는 어렵다. 고증보다는 여주인공 의 발랄하고 활동적인 이미지를 강화하기 위해 의상의 조형 요 소들을 적극 활용한 것으로 보인다. 아버지의 장례식 장면에서 는 유일한 한복인 상복(Image 23)을 착용하였는데, 삼베로 만 든 포건, 수질, 대수, 장군, 요질 등 여자의 전통 상복을 갖추 어 입고 있어 소재와 형태 등에 있어 조선 말기의 전통 상복 
Table 2. Costumes of the main female character in $<$ YMCA Baseball Team $>$

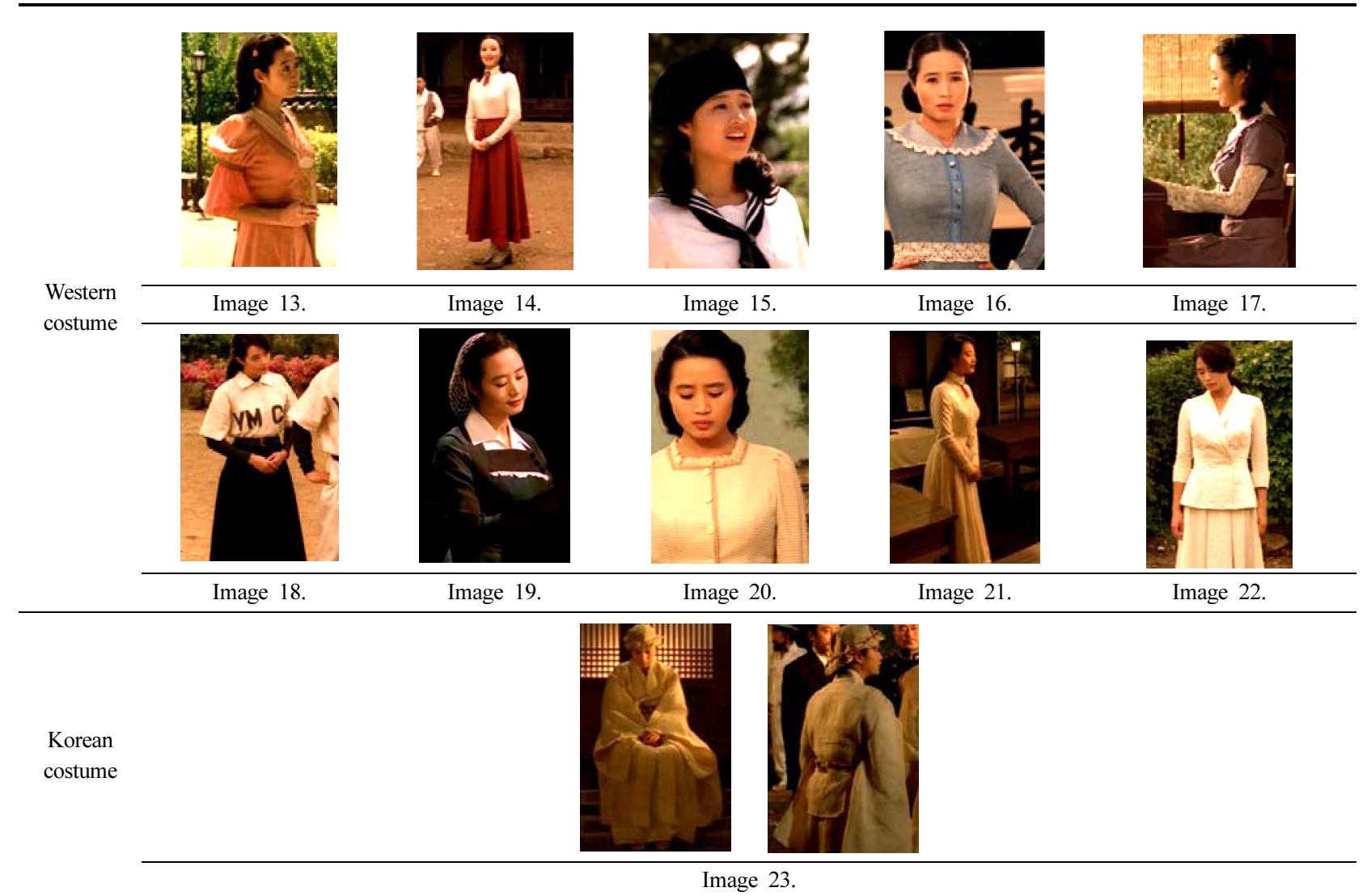

에 충실하고자 한 것으로 이해된다.

\section{3. 그림자 살인}

<그림자 살인>의 배경은 을사조약이 체결된 1905년부터 고 종 황제가 헤이그에 특사를 파견한 1907년까지이다. 탐정 홍진 호와 의학도 장광수가 여주인공인 여류발명가 박순덕의 도움을 받아 아동 성매매, 마약 거래 등 추악한 면을 숨긴 서커스단 단장과 고위 관리들의 실체를 파헤치는 이야기를 그리고 있다. <그림자 살인>에서는 박순덕의 의상이 총 7 벌 등장하는데, 그 중 양장은 2 벌, 한복은 5 벌이다. 2 벌의 양장 가운데 1 벌은 박 순덕이 홍진호와 장광수를 돕기 위해 남장을 한 것이다. 이는 특수한 장면의 상황에서 연출된 의상이므로 본 연구의 성격과 맞지 않아 제외하였다. 나머지 1 벌의 양장과 5 벌의 한복에 대 해 영화의 전개 순서대로 번호를 붙여 정리한 결과는 Table 3 과 같다.

먼저 조형성을 살펴보면, 박순덕이 미국으로 유학을 떠나는 마지막 장면에서 등장하는 검정색 양장의 외형은 대체로 $\mathrm{S}$ 자 형 실루엣이며, 색상은 무채색을 기본으로 페일 톤, 파스텔 톤 등 톤인톤 배색을 하였다(Image 24). 소재는 견, 모, 벨벳 등 당시 상류층만이 입을 수 있었던 고급스러운 소재들을 사용하
여 신분을 드러내고 있다. 남장을 하고 외출하는 장면과 미국 으로 유학을 떠나는 마지막 장면(Image 24)을 제외하고 박순덕 의 의상은 모두 한복이다. 한복의 외형은 전통적 한복과 변형 된 요소가 있는 한복이 모두 보였다. 한복의 색상에서는 페일 톤, 파스텔 톤 등의 톤인톤 배색의 사용으로 여성스럽고 우아 한 이미지를 연출하기도 하고, 경우에 따라서는 갈색과 회색 등 어둡고 탁한 색상의 사용으로 용감하고 호전적인 활동의 분위 기를 연출하기도 했다.

박순덕 의상의 고증 충실도를 살펴보면, 양장의 경우 당시의 깁슨 걸 룩의 외관을 비교적 잘 보여주고 있다고 여겨진다. 한 복은 전통적 한복과 변형된 요소가 있는 한복이 모두 등장한다. 먼저 전통 한복을 살펴보면, 당시 유행했던 왜소하고 짧은 길이 의 저고리에 비해 전반적으로 풍성한 모습이며, 넓은 깃과 동 정, 긴 고름, 깃과 수구의 모던한 소재 사용 등에서 현재 유행 하는 한복의 분위기가 느껴진다. 영화에서 변형 한복을 입힌 것 은 1900 년대 후반 무렵에 통치마 등 개량 한복이 등장하기 시 작했다는 역사적 사실에 비추어 볼 때 전혀 근거 없는 설정은 아니라고 할 수 있다. 다만 박순덕이 착용하고 있는 변형 한복 의 형태는 개량된 치마허리, 짧은 통치마 등과 같은 역사적 사 실과는 별로 상관이 없는 듯하다. 셔츠 칼라의 블라우스처럼 변 
Table 3. Costumes of the main female character in $<$ Private Eye(Geurimja Sarin) $>$

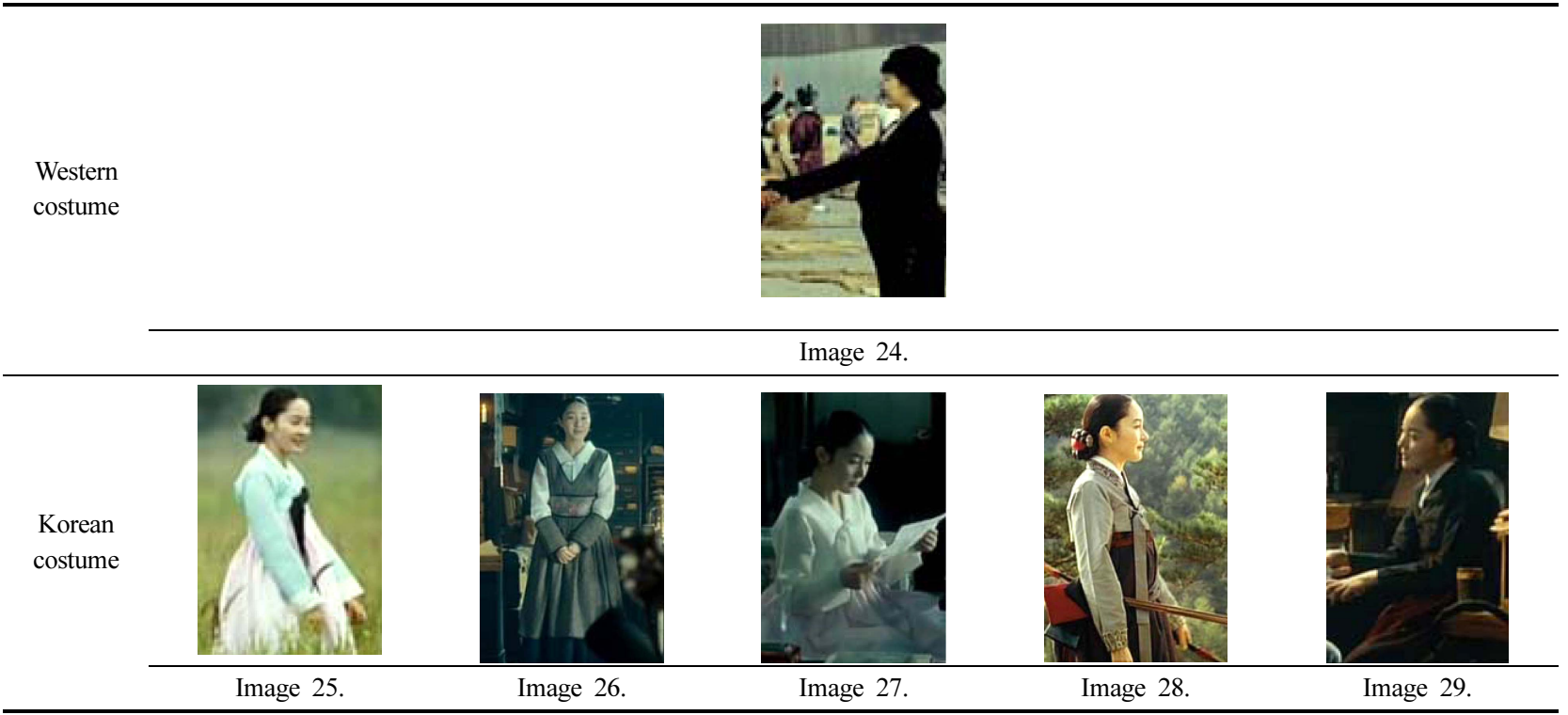

Media Content :Image. 24 29. Costumes in <Private Eye(Geurimja Sarin)>. $<$ Private Eye (Geurimja Sarin) $>$ official DVD (November 22nd 2013).

형된 저고리(Image 26 27), 리본처럼 달린 고름(Image 26 27), 조끼허리가 달린 오버 스커트와 같은 앞치마(Image 26) 등에서 고증과는 무관한 변형을 발견할 수 있다. 고름 대신 매듭을 단 저고리(Image 29)도 보이는데 겉저고리에 매듭단추를 사용하는 설정 역시 시기적으로 너무 이른 것으로 여겨진다.

이상의 분석 결과를 정리하면 Table 4 와 같다.

\section{4. 영화 의상의 상징적 이미지}

\section{1. 가비}

$<$ 가비>의 여주인공 따냐의 인물 특성을 살펴보면 다음과 같 다. 따냐는 역관의 딸로 태어났으나, 아버지가 역적으로 누명을 쓰고 죽임을 당한다. 그 후 러시아에서 도적 생활을 하며 자유
롭게 살아가던 따냐는 연인인 일리치와 함께 러시아 군용기차 를 털다 일본에게 붙잡혀 고종 암살 작전에 가담하게 된다. 따 냐는 러시아어에 능통한데다 뛰어난 바리스타이기도 해서, 러 시아에 사신으로 온 민영환의 마음을 얻어 조선으로 들어온 후 조선의 러시아 공사관에서 고종에게 커피를 진상하는 일을 맡 게 된다. 고종은 처음에는 따냐를 경계하다가 조금씩 마음을 열 고 심적으로 의지하게 되고, 개인사적 이유로 인해 자신을 조 선인으로 인정하지 않던 따냐도 시간이 흐르고 고종의 신뢰를 받게 되면서 자신의 민족 정체성에 대해 고민하게 된다.

따냐가 지닌 신여성적 면모를 살펴보면 다음과 같다. 따냐는 아버지를 잃고 어린 시절부터 러시아에서 자랐기 때문에 서구 환경에서 교육을 받은 신여성이라고 볼 수 있다. 또한 바리스 타라는 전문적 직업을 가지고 있어 여성의 사회적 진출이 어려

Table 4. Visual image of Western costume and Korean costume in $<$ Gabi $>$, $<$ YMCA Baseball Team $>$, and $<$ Private Eye(Geurimja Sarin) $>$

\begin{tabular}{|c|c|c|}
\hline & Western costume & Korean costume \\
\hline$<$ Gabi $>$ & $\begin{array}{l}\cdot \text { Based on Gibson Girl-style } \\
\cdot \text { Luxurious textiles } \\
\cdot \text { Dignified and elegant image } \\
\cdot \text { Based on historical researches but more focused on image making }\end{array}$ & $\begin{array}{l}\cdot \text { White court ladies' costume(national mourning dress) } \\
\cdot \text { Reflection of current trends of Korean costume }\end{array}$ \\
\hline $\begin{array}{l}<\text { YMCA } \\
\text { Baseball } \\
\text { Team }>\end{array}$ & $\begin{array}{l}\cdot \text { Generally S-silhouette } \\
\cdot \text { Relatively simple and plain } \\
\cdot \text { Bright and active image } \\
\cdot \text { Focused on the design modification more than on historical researches }\end{array}$ & $\begin{array}{l}\text { Hemp mourning dress based on historical researches of } \\
\text { traditional female dress in the late Joseon dynasty }\end{array}$ \\
\hline $\begin{array}{l}<\text { Private Eye } \\
(\text { Geurimja } \\
\text { Sarin })>\end{array}$ & $\begin{array}{l}\text { - Based on Gibson Girl-style } \\
\cdot \text { Luxurious textiles such as silk and velvet } \\
\cdot \text { Based on historical researches }\end{array}$ & $\begin{array}{l}\cdot \text { Various color tone } \\
\cdot \text { High-class textiles such as silk and wool } \\
\cdot \text { Reflection of current trends of Korean costume } \\
\cdot \text { Coexistence of traditional forms and modified forms } \\
\text { - Some modifications that have nothing to do with } \\
\text { historical researches }\end{array}$ \\
\hline
\end{tabular}


웠던 당시의 사회적 상황을 고려해 볼 때 역시 신여성으로 이 해가 가능하다. 따냐는 내면적으로는 구속을 싫어하고 자기주 장이 뚜렷하지만, 대외적으로는 성숙하고 진지하며 격식을 차 릴 줄 아는 교육 받은 신여성이다. 가비>에서는 아관파천의 암울한 상황에서 고종의 두렵고 외로운 심정과 신문물인 커피 를, 따냐라는 여성을 통해 보여주고 있다. 여주인공 따냐의 모 습에는 신문물에 개방적이었고 고종이 의지했던 실존 여성 엄 귀비의 모습이 투영된 듯하기도 하다.

$<$ 가비>에서는 총 17 벌의 양장과 1 벌의 한복이 등장한다. 양 장의 수가 압도적으로 많다. 양장은 성숙하고 진지하며 격식을 차린 교육 받은 신여성으로서의 따냐를 대외적으로 보여주는 대표적 상징물이다. 반면, 한복은 고종의 신뢰를 얻기 위해 의 도적으로 착용하는 것으로 보다 내면적이고 은밀한 따냐의 심 리 상태를 보여주는 도구이다. 또한 한복은 따냐가 스스로의 민 족 정체성을 고민하게 되는 시점을 암시하는 상징물이기도 하 다. 따라서 가비>에서 따냐가 착용한 양장과 한복은 대외성과 내면성의 의미관계로 대별되고 있으며, 동시에 민족 정체성 부 정과 긍정의 의미관계로 대별되고 있다고 할 수 있다.

영화 <가비>에서 양장과 한복이 암시하는 대외성과 내면성 의 상징적 이미지는 근현대 한국 사회에서 양복과 한복이 담당 했던 역할을 소급 적용한 결과로 해석된다. 20세기 중반 이후 일상복이 서구화되는 과정에서 양복은 공적인 공간에 적합한 의상으로 빠른 속도로 자리 잡아 간데 비해, 한복은 사적인 공 간에서 좀 더 오래 남아 있을 수 있었다. 양장과 한복을 바라 보는 근현대적 시선이 대한제국을 시대적 배경으로 하는 영화 $<$ 가비>에서도 고스란히 투사된 것이다.

가비>에서 양장과 한복이 암시하는 또 하나의 이미지, 즉 민 족 정체성 부정과 긍정의 상징적 이미지는 양장과 한복의 기원 과 관련한 민족적, 문화적 정체성에 대한 근현대적 인식을 어느 정도 반영한 것이다. 실제로도 개화기 당시의 양장은 반민족적 인 매국노 집단과 친일파의 상징으로 여겨지기도 했으며(Lee, 2001), 1950년대에는 양공주라 불리는 특수한 직업여성의 복장 으로 인식되는 경우도 있었다(Kim, 2007). 지금도 한복은 한민 족 문화 정체성을 드러내는 중요한 수단으로 여겨지고 있다.

\section{2. $\mathrm{YMCA}$ 야구단}

$<\mathrm{YMCA}$ 야구단>의 여주인공 민정림의 인물 특성을 살펴보 면 다음과 같다. 민정림은 미국에서 유학생활을 하면서 야구 클 럽 활동을 했을 정도로 활동적인 여성으로 귀국 후 $\mathrm{YMCA}$ 야 구단의 감독을 맡게 된다. 여성의 사회 활동이 거의 없던 시절 이었기 때문에 남자 단원들을 처음 마주했을 때 무시당하기도 하지만, 단원들을 잘 설득하고 대처하는 밝은 성격의 소유자이 다. 또한 을사조약 체결에 죽음으로 항거한 아버지 시종무관장 민공의 뒤를 이어 의병대원으로서 활동하는 등 주체적인 인물 이다. 민정림은 통감부 수배령 중에도 자신의 단원들과 일본 야 구팀과의 시합에 참석하러 돌아오는 등 의리가 있는 여성이기 도 하다.
민정림이 지닌 신여성적 면모를 살펴보면 다음과 같다. 민정 림은 미국 유학을 다녀왔으므로 신교육을 접한 신여성으로 이 해 할 수 있다. YMCA에 실제로 야구단이 있었던 해는 1905 년이었다(Korean Baseball History Publication Commission, 1999). 이 야구단에 실제로 여성이 포함되었는지 여부는 확실 히 알려진 바가 없으나, 영화에서는 여성캐릭터가 필요했던 것 으로 보인다. 남자 단원들은 대부분 전통적인 인물들로 설정되 고, 야구단 그 자체는 서구 문화의 일부이다. 민정림은 전통적 인 인물들과 서구적 신문화를 매개하는 역할을 하고 있다. 또 한 주체적이고 활동적인 면에서 당시의 전통적 여성상과는 전 혀 다른 신여성적 면모를 지닌 인물이다. 당시 미국 유학을 마 치고 귀국했던 실존 인물로는 1900년 의학박사학위를 받은 박 에스더, 1906년 학사학위를 받은 하란사 등이 있다. 민정림이 라는 신여성을 창조하는데 이러한 실존 인물들이 모델이 되었 을 것으로 추정된다.

$<\mathrm{YMCA}$ 야구단>에서는 총 11 벌의 양장과 1 벌의 한복이 등 장한다. 가비>와 마찬가지로 양장의 수가 압도적으로 많다. 양 장은 민정림이 주체적으로 야구단을 조직해 가는 과정에서 평 상시에 항상 착용하고 있는 의상이다. 반면, 한복은 민정림의 밝고 의욕적인 평소 모습과는 달리 아버지의 장례식에서 상주 로서 슬픔과 실의에 잠긴 모습으로 착용한 옷이다. 따라서 $<\mathrm{YMCA}$ 야구단>에서 민정림이 착용한 양장과 한복은 일상성 과 의례성으로 대별되고 있으며, 동시에 역동성과 정체성(停滯 性)의 의미관계로 대별되고 있다고 할 수 있다.

영화 <YMCA 야구단>에서 양장과 한복이 드러내는 일상성 과 의례성의 이미지 역시 현대 한국 사회에서 양장과 한복이 담당하는 역할이 투영된 것으로 보인다. 일상복이 서구화되는 과정에서 양장은 평상시에 적합한 옷으로 인식되어 갔으며, 한 복은 특별한 날의 외출복이나 예복으로 정착해 갔다. 지금도 평 소에는 양장을 착용하고, 결혼식과 장례식 등의 특별한 의례에 서 가족이나 일부 친지들은 한복을 착용한다.

또한 <YMCA 야구단>에서 양장과 한복이 드러내는 또 하 나의 이미지, 즉 역동성과 정체성(停帶性)의 이미지에는 양장과 한복에 대한 대중적 인식이 반영되어 있다고 여겨진다. 19세기 말, 20 세기 초 개화 세력과 일제 강점기 근대화에 앞장섰던 사 람들은 양복을 시대의 변화에 적합하고 활동하기에 편리한 기 능적인 옷으로 인식했으며, 반대로 한복은 개선의 대상이며 시 대착오적인 옷으로 인식되는 경향이 있었다. 양복과 양장이 기 능적이고 실용적인 옷이라는 인식은 20 세기 중반 이후 산업화 시기에도 이어져 왔으며, 지금도 많은 한국 사람들은 한복을 다 소 불편한 옷이라고 여기고 있다. 기능성과 불편함을 주된 속 성으로 하는 양장과 한복에 대한 대중적 인식은 역동성과 정체 성(停滯性)의 이미지로 영화에서 포장되고 재배치되어 은밀하 게 보여지고 있다.

\section{3. 그림자 살인}

<그림자 살인>의 여주인공 박순덕의 인물 특성을 살펴보면 
다음과 같다. 박순덕은 비밀리에 여류 발명가로 활동하고 있으 며, 서구식 과학 교육을 받아 발명, 실험, 추리 등에 능숙한 인 물이다. 과거에 홍진호가 박순덕의 친위대였다는 극중 대사로 미루어 보아 박순덕은 왕가 또는 지체 높은 가문의 일족이었을 것으로 추측된다. 박순덕은 서양식 신문물 교육을 받았음에도 담장 안에 갇힌 사대부 집안의 부인으로서 자신의 삶을 영위하 고 있다. 사회적 신분의 제약으로 인해 학문에 대한 열정을 접 은 채 살았지만, 결국은 유학길에 오르게 된다.

박순덕의 신여성적 면모를 살펴보면 다음과 같다. 실험실에 놓 은 플라스크 등과 같은 다양한 서구식 과학 기구들, 본인이 발 명한 은청기(은밀하게 듣는 도구), 그리고 능숙하고 뛰어난 현장 감식 능력 등으로 미루어 볼 때 박순덕은 높은 수준의 서구 과 학 교육을 접한 인물로 추정된다. 또한 유학을 가고 싶은 의지 가 강하며, 결국 영화의 마지막에서 미국 유학길에 오르는 모습 이 보이면서 박순덕의 신여성적 면모가 드러나고 있다.

<그림자 살인>에서는 총 2 벌의 양장과 5 벌의 한복이 등장한 다. 양장이 압도적으로 많았던 다른 두 편의 영화와는 대조적 이다. 박순덕의 양장은 주체적으로 자신의 삶을 개척하겠다는 마음의 결단과 새로운 삶에 대한 의지를 나타낸다. 반면, 한복 은 박순덕이 전통을 고수하는 사대부가 부녀자의 신분 굴레에 갇혀 있음을 상징적으로 보여준다. 따라서 <그림자 살인>에서 박순덕이 착용한 양장과 한복은 주체성과 순응의 의미관계로 대별된다고 할 수 있다. 또한 박순덕이 유학길에 오르면서 착 용하는 양장과 그 이전에 계속 착용하는 한복은 변화성과 지속 성의 의미관계로 대별된다고 할 수 있다.

영화 <그림자 살인>에서 양장과 한복이 암시하는 주체성과 순응의 상징적 이미지는 식민 통치 기간 동안 일제가 심으려 했던 이데올로기와 연결되는 부분이 있다. 일제는 식민지 교육 을 통해 한국의 전통과 민족 문화는 미개하고 열등한 대상이라 는 열등성-종속성 - 타율성 등의 역사관을 통치 기간 내내 주 입하였다(Lee, 2011). 일제 주도 하에 근대화가 진행되면서 한 복은 전근대적인 것으로 개선과 개량의 대상이 되었고, 의복 개 량은 전통 한복의 단점만을 강조하여 식민지 피지배인으로서의
열등의식을 갖게 하는 요인으로 작용했다(Jeon et al., 2004). 또한 일제는 여학교의 '현모양처' 교육 정책을 통해 순종하는 여성상을 형성하려 하였고, 그러한 여성상이 식민 질서의 안정 을 위해 역할을 담당할 것을 기대했다(Kang, 2009). 한복을 착 용한 박순덕의 이미지는 신여성보다는 현모양처에 가깝고, 현 실적 제약에 순응하고 원하는 것을 포기해야만 하는 전근대적 여성상을 상징한다. 또한 보다 행복한 삶을 추구하기 위해 개 선되어야 할 부분이 있음을 암시한다. 반면 양장을 착용한 이 미지는 가정과 사회가 요구했던 기존의 순종적인 태도를 벗어 나 자신의 삶을 주체적으로 꾸려 나가는 근대적 여성상을 상징 한다.

<그림자 살인>에서 양장과 한복이 암시하는 또 다른 이미지, 즉 변화성과 지속성의 상징적 이미지는 근대성과 전통성에 '변 화의 속도라는 변수를 대입함으로써 얻어진 도식으로 이해된 다. 즉, 서구 근대사회는 변화의 속성을 근간으로 하며 양장은 이를 대변한다. 반면 전통사회는 변화에 더디며 한복이 이를 대 변하는 것이다. 박순덕은 전통적 한복과 변형된 한복을 모두 착 용하는데, 두 유형의 한복에서도 미묘한 변화의 속도 차이를 감 지할 수 있다. 두 유형의 한복은 영화의 장면에 따라서 다르게 사용되는 경향이 있다. 전통적 한복은 사대부가 여인으로서 역 할을 수행해야 하는 상황에서 주로 착용되고, 변형된 한복은 신 교육을 받거나 실험과 발명 등 신문화와 관련된 새로운 활동을 하는 상황에서 주로 착용된다. 전통적 한복을 통해서 신여성이 지만 이를 감추고 전통의 영역 내에 머무를 수밖에 없는 현실 을 드러냈으며, 변형된 한복을 통해서 보다 진보적인 여성상을 드러낸 것이다.

이상의 분석 결과를 정리하면 Table 5 와 같다.

\section{5. 결 론}

본 연구는 최근 10 년간 제작된 한국 영화 중 대한제국 시기를 배경으로 하는 세 편의 영화 <가비>, <YMCA 야구단>, <그림 자 살인>을 대상으로 각 영화에서 신여성적 면모를 지니는 여

Table 5. Symbolic image of Western costume and Korean costume in $<$ Gabi $>$, $<$ YMCA Baseball Team $>$, and $<$ Private Eye(Geurimja Sarin) $>$

\begin{tabular}{|c|c|c|c|}
\hline & $\begin{array}{l}\text { Symbolic image of } \\
\text { Western costume }\end{array}$ & $\begin{array}{l}\text { Symbolic image of } \\
\text { Korean costume }\end{array}$ & Meaning \\
\hline \multirow{2}{*}{$<$ Gabi $>$} & Externality & Internality & $\begin{array}{l}\text { Reflection of symbolic meaning of Western and Korean costume in } \\
\text { modern Korean society }\end{array}$ \\
\hline & $\begin{array}{l}\text { Denial of national } \\
\text { identity }\end{array}$ & $\begin{array}{l}\text { Affirmation of } \\
\text { national identity }\end{array}$ & $\begin{array}{l}\text { Reflection of modern cognition of national and cultural identity related to } \\
\text { the origin of Western and Korean costume }\end{array}$ \\
\hline \multirow{2}{*}{$\begin{array}{c}<\text { YMCA } \\
\text { Baseball Team }>\end{array}$} & Dailiness & Ceremonialness & $\begin{array}{l}\text { Projection of roles of Western(daily) and Korean costume(ceremonial) in } \\
\text { contemporary Korean society }\end{array}$ \\
\hline & Dynamics & Statics & $\begin{array}{l}\text { Reflection of public perception on Western costume(functional) and } \\
\text { Korean costume(uncomfortable) }\end{array}$ \\
\hline \multirow{2}{*}{$\begin{array}{c}<\text { Private Eye } \\
(\text { Geurimja Sarin) }>\end{array}$} & Independence & Conformity & $\begin{array}{l}\text { Reflection of colonial ruling ideology by Japan during the Japanese } \\
\text { colonial period }\end{array}$ \\
\hline & Variability & Continuity & Interpretation of modernity and traditionality in terms of speed of change \\
\hline
\end{tabular}


주인공의 의상의 시각적 이미지와 상징적 이미지를 분석하였다.

첫째, 조형적 특성을 기준으로 각 영화 신여성 의상의 시각 적 이미지를 살펴본 결과는 다음과 같다. <가비>와 < $<\mathrm{YMCA}$ 야구단>의 경우 양장 의상이 대부분인 반면 <그림자 살인>의 경우 한복 의상이 주로 등장했다. 조형적으로 양장 의상들은 당 시 서양에서 유행했던 깁슨 걸 스타일을 반영하여 $\mathrm{S}$ 자형 실루 엣, 아랫단으로 갈수록 퍼지는 긴 치마, 레그 오브 머튼 소매 (leg-of-mutton sleeve) 등의 특징을 보인다. 그러나 각 영화별 로 조금씩 차이가 있으며, 이는 양장 의상이 인물의 이미지를 연출하기 위한 시각적 장치로 사용되었기 때문인 것으로 보인 다. 한복 의상은 <가비>에서는 궁녀복, $<\mathrm{YMCA}$ 야구단>에서 는 상복으로 두 영화에서는 특수복, 전통적인 형태의 한복으로 등장하지만, <그림자 살인>에서는 외출복이나 일상복, 작업복 의 형태로 고루 등장하며 전통적 한복과 변형된 요소가 있는 한복이 모두 보였다.

둘째, 고증 충실도를 기준으로 시각적 이미지를 살펴본 결과, 세 영화 모두 19 세말과 20 세기 초라는 시대적 배경을 토대로 의 상이 디자인되었으나 세 영화의 고증 충실도가 동일하지는 않 았고 인물의 성격이나 영화 속 상황에 따라 일부 변형되는 부 분도 있었다. 양장의 경우 < $\mathrm{YMCA}$ 야구단>은 다른 두 편에 비해 상대적으로 고증에 충실하지 않은 편이었는데, 이는 인물 의 성격 표현을 극대화하기 위해서였던 것으로 보인다. <가비 >의 양장 가운데 특히 시스루 블라우스와 날염 블라우스 등은 고증보다는 디자인이나 시각적 이미지 연출에 더 주안점을 둔 대표적 경우였다. 한복의 경우 < 가비>와 <그림자 살인>에서 당 대보다는 현재의 한복 디테일 유행이 반영된 부분이 있었으며, 특히 <그림자 살인>에서는 영화의 시대적 배경에 비해 변형된 한복이 시기적으로 조금 일찍 등장한다고 볼 수 있는데다 변형 된 요소도 역사적 사실과는 큰 관련이 없는 편이었다.

셋째, 인물 특성과 신여성적 면모를 토대로 각 영화 신여성 의상의 상징적 이미지를 살펴본 결과는 다음과 같다. 세 영화 모두 같은 시대를 배경으로 하고 여주인공들이 신여성이라는 공통점이 있으나, 표현된 인물의 성격과 신여성적 면모는 다소 달랐다. 따라서 양장과 한복의 의미 관계로 드러나는 의상의 상 징적 이미지에도 다소 차이가 있었다. 영화 <가비>에서 양장과 한복은 대외성과 내면성의 이미지, 민족 정체성 부정과 긍정의 이미지로 대별되어 나타나고 있었다. 영화 < $\mathrm{YMCA}$ 야구단>에 서 양장과 한복은 일상성과 의례성의 이미지, 역동성과 정체성 (停滯性)의 이미지로 대별되어 있었으며, 영화 <그림자 살인> 에서 양장과 한복은 주체성과 순응의 이미지, 변화성과 지속성 의 이미지로 대별되어 나타났다. 영화에서 암시하는 양장과 한 복의 상징적 이미지는 19 세기 말과 20 세기 초 당시의 사실적 이미지라기보다는 근현대 이후 한국인이 한복과 양장에 대해 투영해 왔던 이미지가 반영된 경우가 많았다. 이는 현재 대중 에게 친숙한 한복과 양장의 이미지를 택함으로써 인물의 성격 이나 영화의 상황 설명에 있어서 관객과 더욱 원활한 소통을 하기 위한 노력의 일환이라고 볼 수 있다. 이처럼 영화 의상이
비언어적으로 관객과 영화 제작자의 기호와 약속으로 작용함을 확인할 수 있었다.

본 연구는 세 편의 영화에 한정되었고 여주인공 역할과 비 중이 달랐으므로 한복과 양장의 이미지를 일반화하기에는 제약 이 있을 것이다. 본 연구가 하나의 해석 시도로서 이해되기를 바라며, 영화 의상 연구의 지평을 확대하는데에 도움이 되기를 바란다.

영화 의상은 조형적 특성과 고증의 정도에 따라 시각적 이 미지를 드러내는 영화적 장치로서 효율적 수단이 되며, 동시에 매우 은밀하고 정교하게 고안된 상징적 이미지를 통해 감독과 디자이너, 그리고 더 나아가 관중들의 의식과 무의식 세계를 보 여주는 중요한 수단이 될 수 있다. 영화 의상은 영화의 시대적 배경, 장면 설정, 인물 특성 등을 드러내기 위해 창조되는 유 형의 물질적 대상이지만, 이 물질적 대상에는 영화를 만드는 감 독과 의상을 만드는 의상 디자이너의 의상에 대한 인식과 태도 가 은연중에 반영되어 있다. 대부분의 영화는 대중들의 공감을 얻고 사회적 기호를 예측하며 제작되므로 영화 의상에는 또한 한국 사회 대중들의 의상에 대한 인식과 태도가 반영되어 있다 고도 볼 수 있다. 비록 영화 의상을 통해서이지만, 양장과 한 복의 의미 관계를 통해 드러나는 상징적 이미지는 우리 사회의 대중적 인식과 태도의 자화상이라고도 할 수 있을 것이다.

\section{References}

Busan Modern History Museum. (2009). The journey to the modernity. Seoul: Minsokwon.

Calasibetta, C. M. (2006). Fairchild's dictionary of fashion (K. W. Park, Trans.). Busan: Norano. (Original work published 1998)

Choi, E. S. (2001). Costume of the Korean enlightenment and Japanese colonial periods. In ministry of culture, sports and tourism \& Korean costume culture 2000 years organizing committee. Two thousand years of Korean fashion, (pp. 119-132). Seoul: Misul Munhwa.

Delong, M. R. (1987). The way we look. Ames: Iowa State University Press.

'Esther and Yousan Pak, Dr. Rosetta Hall, Sherwood and Edith, Sept. 1895' (2009). Retrieved November 9, 2013, from http://blog.joins.com/ media/index.asp?uid $=$ spirit0104\& folder $=0 \&$ day $=200901$

Go, B. J. (2001). Korean life history of 100 years: Clothing. Seoul: Hyeonamsa.

Jeon, G. O., Byeon, S. W., Park, J. S., \& Kim, E. J. (2004). Cultural history of Korean women. vol.l. Seoul: Sookmyung Women's University Research Institute of Asian Women.

Jeong, M. K. (2001). The beginning of modern women education. In Gilbaksesang, 20th century women's event history: From the beginning of modern women education to cyber feminism, (pp. 1525). Seoul: Women's news Inc.

Jeong, T. U., Choe, J. Y., Lee, J. H. (Producer), \& Chang, Y. H. (Director). (2011). Gabi [Motion picture]. Korea: Ocean Film.

Jo, M. J. (2013). Other's view of new woman in early twentiethcentury Korea. Korean Language Research, 32, 279-309. 
Kang, J. M. (2009). Mother's history of suffering. Seoul: Inmulgwasasangsa.

Kim, E. J., \& Yim, L. (2009). Changes of Korean dress in history. Gwangju: Chonnam National University Press.

Kim, J. H., \& Kim, Y. S. (2014). A study on expression types of fantasy in movie costumes for "Alice in wonderland": Focused on the theory of fantasy in literature. Fashion \& Textile Research Journal, 16(1), 26-34. doi: 10.5805/SFTI.2014.16.1.26

Kim, M. J. (1989). A study on the woman's costume and thoughts in the Chosun dynasty. The Journal of Seoul Woman's University, 18, 391-426.

Kim, S. J. (2007). Reading the transformations of women's clothes in postcolonial Korea: Gender politics of tradition and modernity. Issues in Feminism, 7(2), 281-320.

Kim, S. J. (2009). Excess of the modern: The New Woman in colonial Korea, 1920-1934. Seoul: Somyong Publishing Co.

Korean Baseball History Publication Commission. (1999). History of Korean baseball. Seoul: Korea Baseball Association \& Korea Baseball Organization.

Lee, B. Y. (2005). Korean women in history. Seoul: Eojinee.

Lee, I. S., Kim, M. J., \& Byun, M. Y. (2006). A study on the heroine's costumes in the movie titled YMCA baseball team: By focusing on the costumes when the country opened itself to the outside world. The Research Journal of the Costume Culture, 14(5), 728738

Lee, J. S. (2001). Westernization and changes in Korean traditional culture: Focused on food, clothing, and shelter culture. Zeitschrift der Koreanisch-Deutschen Gesellschaft fur Sozialwissenschaften, 11(1), 209-225.

Lee, K. M. (2008). Western-styled court costume paradigm of the Korean empire. Unpublished doctoral dissertation, Seoul National University, Seoul.

Lee, M. H. (2011). Ideology of Japanese compulsory annexation of Korea and colonial education policy. Korean Independence Movement History Research, 39, 77-126.
Lee, S. Y., Han, S. K. (Producer), \& Park, D. M. (Director). (2009). Private Eye(Geurimja Sarin) [Motion picture]. Korea: CJ E\&M.

Lim, S. J., Ryu, E. J., \& Park, H. W. (1994). Study on the history of the development of Korean female costume during the 100 years after the floweringtime. The Research Journal of the Costume Culture, 2(2), 203-223.

National Institute of Korean History. (2003). Hanguksa. vol.44. Gwacheon: National Institute of Korean History.

National Palace Museum of Korea. (2010). 100 years past: Memories of the Korean Empire. Seoul: National Palace Museum of Korea.

Park, Y. M. (2012). Revolution of Korean dress, the haircutting decree and Western dress. Cultural Heritage Administration of Korea Heritage Channel. Retrieved November 2, 2013, from http://www. heritagechannel.tv/hp/hpContents/story/view.do?contentsSeq $=927 \&$ categoryType $=2$

Shin, H. S. (2008). 100 years of Western costume in Korea. Seoul: Misul Munhwa.

Shim, J. M., Lee, U. J. (Producer), \& Kim, H. S. (Director). (2002). YMCA Baseball Team [Motion picture]. Korea: Myung Films.

Suyu+Nomo Modern Media Research Team. (2005). New Woman. Seoul: Hankyoreh Media Company.

The National Institute of the Korean Language (2008). 신 여성. Standard Korean Language Dictionary. Retrieved October 5, 2013, from http://stdweb2.korean.go.kr/main.jsp

Yi, Y. K., \& Kim, J. K. (1995). The process and the characteristics of western clothing adoption of Korea: Corelating with cultural diffusion theory. Journal of the Korean Society of Costume, 26, 123-143.

Yu, J. Y. (2007). The comparison of the modern women dress of Korea and Japan. Unpublished master's thesis, Hongik University, Seoul.

(Received 23 November 2013; 1st Revised 24 December 2013; 2nd Revised 18 June 2014; 3rd Revised 23 June 2014;

Accepted 23 July 2014)

Copyright $(\mathbb{C} 2014$ (by) the authors. This article is an open access article distributed under the terms and conditions of the Creative Commons Attribution license (http://creativecommons.org/licenses/by/3.0/), which permits unrestricted use, distribution, and reproduction in any medium, provided the original work is properly cited. 